\title{
Heterogeneous Expression of Phenobarbital-Inducible Cytochrome P-450 Genes within the Hepatic Acinus in the Rat
}

\author{
Jose Chianale, Caroline Dvorak, Maryann May and Jorge J. Gumucio \\ Department of Internal Medicine, Section of Gastroenterology, Veterans Administration Medical Center and the University of \\ Michigan School of Medicine, Ann Arbor, Michigan 48105
}

\begin{abstract}
Within the hepatic acinus, the functional unit of liver parenchyma, the induction of cytochrome $P-450$ protein by phenobarbital is manifested primarily in hepatocytes located closer to the hepatic venule, i.e., distal hepatocytes. The objective of this study was to determine the levels of cytochromes $P-450 b$ and $P-450 e$ mRNAs in populations of hepatocytes originating in the proximal or distal half of the liver acinus in the rat, as an approach to the elucidation of the mechanisms responsible for the heterogeneous zonal expression of cytochrome P-450 protein. The development of a new method to isolate hepatocytes originating from the proximal or distal half of the liver acinus enabled the measurement of total cytochrome $P-450$ content and of cytochromes $P-450 b$ and $P-450$ e mRNAs in these hepatocytes. Levels of cytochromes $P-450 b$ and $P-450 e$ mRNAs were assessed in proximal and distal hepatocytes by Northern blot hybridization of poly $(A+)$ RNA with a cDNA recognizing sequences of these two cytochromes. The kinetics of induetion were defined by measuring these parameters after a single phenobarbital injection. Cytochrome $P-450$ mRNA levels reached maximum induction at 16 hr, returning to basal values by $48 \mathrm{hr}$. In contrast, total cytochrome $P-450$ microsomal protein content reached maximum induction after $33 \mathrm{hr}$. Hepatocytes of the distal half of the hepatic acinus responded to phenobarbital with higher levels of cytochromes $P-450 b$ and $P-450 e$ mRNAs than proximal hepatocytes. These results indicated that there is modulation of the expression of the cytochromes $P-450 \mathrm{~b}$ and $P-450 \mathrm{e}$ genes within the hepatic acinus.
\end{abstract}

The hepatic acinus is a tridimensional mass of hepatocytes perfused by a terminal portal venule and a terminal hepatic arteriole located at the core of the acinus (1). Blood moves from these vessels into the liver sinusoids, establishing contact with hepatocytes through sinusoidal fenestrations. After perfusing the acinar hepatocytes, blood exits the acinus via two or more hepatic venules located at the periphery of this tridimensional

Received January 13, 1986; accepted May 16, 1986.

This study was supported in part by Grant AM 32842 from the National Institute of Health, by Merit Review Award from the Veterans Administration and by The American Liver Foundation.

Dr. Chianale is a recipient of an American Liver Foundation Fellowship.

Address reprint requests to: Jorge J. Gumucio, M.D., Department of Internal Medicine, Veterans Administration Medical Center, 2215 Fuller Road, Ann Arbor, Michigan 48105. mass. Perfusion of hepatocytes is therefore unidirectional from the acinar core to the acinar periphery. The result is that solute concentration is highest at the entry of the acinus. As blood moves from the core to the periphery, the concentration of solutes decreases due to the sequential removal of solutes by hepatocytes. Therefore, different microenvironments develop around hepatocytes located closer to the inlet and outlet of the liver acinus. The differences in concentration of oxygen and other solutes in sinusoidal blood surrounding the various zones of the liver acinus most likely play a role in the morphological $(2,3)$, biochemical $(4-6)$ and functional heterogeneity of hepatocytes (7-10). Furthermore, it is plausible that the same microenvironmental differences may also influence zonal gene expression in the liver acinus.

Arbitrarily, the hepatic acinus has been divided into three zones. Zone 1 is closest to the vascular core and is thus perfused with the highest concentrations of substrates. Zone 3 is closer to the acinar outlet and therefore is the last perfused with incoming blood, while Zone 2 is the transitional or intermediate zone (11).

Studies have shown that phenobarbital (PB) induces several forms of cytochrome P-450 in rat liver (12). Of these, cytochromes $\mathrm{P}-450 \mathrm{~b}$ and $\mathrm{P}-450 \mathrm{e}$ are the predominant forms induced (13-15). It has been proposed that, in liver, the molecular mechanism responsible for the PB-mediated cytochrome P-450 induction is an increased rate of transcription of the specific mRNAs (16, 17). All of these studies have been performed using liver homogenates, and therefore did not consider the heterogeneity of liver cells. However, studies using either microspectrophotometric (18) or immunofluorescence techniques $(19,20)$ have shown that the induction of cytochrome $\mathrm{P}-450$ protein by $\mathrm{PB}$ in rat liver is not homogeneous. Rather, cytochrome $\mathrm{P}-450$ is induced predominantly in Zone 3, representing hepatocytes located near the acinar outlet, with the degree of induction decreasing from Zone 3 to Zone 1. What accounts for this zonal induction? Is transcription of cytochromes $\mathrm{P}-450 \mathrm{~b}$ and P-450e genes limited to, or predominant in, hepatocytes of Zone 3? Do all hepatocytes transcribe at similar rate but translate the message with different efficiency? Are there differences in the half-life of the mRNAs in proximal and distal hepatocytes? A serious limitation to the approach of these questions and thus 
to the study of the molecular mechanisms involved in the regulation of the heterogenous expression of cytochrome P-450 within the acinus is the lack of a method of zonal isolation of hepatocytes.

In this study, and as an initial approach to the elucidation of the molecular mechanisms involved in the heterogeneous induction of cytochrome $\mathrm{P}-450$ by $\mathrm{PB}$, the kinetics of PB-mediated induction of cytochromes $P-450 \mathrm{~b}$ and P-450e mRNAs in hepatocytes of different zones of the liver acinus were determined. For this purpose, a new method was developed to isolate hepatocytes of the proximal half (Zones 1 and 2) or distal half (Zones 2 and 3) of the hepatic acinus. While the kinetics of induction of cytochromes P-450b and P-450e mRNAs were similar in all hepatocytes, the levels of induction were higher in hepatocytes isolated from the distal half of the acinus. These results indicated that there are zonal differences in the modulation of cytochromes P-450b and $\mathrm{P}-450 \mathrm{e}$ gene expression in response to $\mathrm{PB}$. This modulation resulted in higher levels of mRNAs in distal hepatocytes; data compatible with the proposal that transcriptional differences among hepatocytes may account for the heterogeneous expression of cytochrome P-450 protein within the acinus.

\section{MATERIALS AND METHODS}

\section{Induction of Cytochrome P-450}

Prior to any experiment, male Sprague-Dawley rats weighing between 180 and $230 \mathrm{gm}$ were kept for at least 1 week under the same environmental conditions. PB was administered i.p. $(80 \mathrm{mg}$ per $\mathrm{kg}$ ) as a single injection, and cell isolation was performed at intervals between 6 and $48 \mathrm{hr}$. To account for possible variations secondary to Circadian rhythm, the time of cell isolation was kept constant (8 to 9 a.m.), while the time of PB injection was varied. Controls were injected with the same volume of the solvent (benzyl alcohol:propylene glycol:water, $1: 30: 19$, v:v).

\section{Isolation of Proximal and Distal Hepatocytes}

Isolation of proximal or distal acinar hepatocytes was performed by a method recently developed in our laboratory (21). This method was validated by using an exogenous label introduced initially into either proximal (Zones 1 and 2) or distal (Zones 2 and 3 ) hepatocytes while in situ. The origin of the subsequently isolated hepatocytes was assessed by following the distribution of this fluorescent label. Once the method had been validated, hepatocytes of the proximal or distal half of the hepatic acinus were obtained: (a) proximal or distal hepatocytes were released by perfusion of the liver with collagenase in either the anterograde (portal to hepatic vein) or in the retrograde (hepatic to portal vein) direction; (b) separation of viable from partially damaged hepatocytes was accomplished by centrifugation of proximal or distal hepatocytes in a Percoll (Pharmacia Fine Chemicals, Piscataway, NJ) density gradient. These two steps were sufficient for the release of proximal or distal hepatocytes. Since in each population of hepatocytes there was overlap with intermediate, Zone 2 hepatocytes, a third step (centrifugal elutriation of proximal or distal hepatocytes) was added. We expected that by subdividing proximal and distal hepatocytes into various fractions, the heterogeneity of response of acinar hepatocytes to the PB-mediated induction of cytochrome P-450 may become better defined. By changing the rate of counterflow, five fractions were obtained from either proximal or distal hepatocytes after centrifugal elutriation.
Since after preliminary attempts it was found that the amount of RNA extracted from each of the five fractions was insufficient, it was decided to combine Fractions II and III as well as Fractions IV and V. Therefore, measurements of cytochromes P-450b and P-450e mRNAs as well as of total microsomal cytochrome $\mathrm{P}-450$ protein were performed in three fractions isolated from proximal or distal hepatocytes: Fraction I; Fraction II-III, and Fraction IV-V.

\section{Measurements of Cytochromes $P-450 b$ and P-450e mRNAs}

Levels of cytochromes P-450b and P-450e mRNAs were measured after $6,16,24,33$ and $48 \mathrm{hr}$ of a single PB dose (80 mg per kg).

RNA Extraction and Isolation of Poly $(A+) R N A$ : Total cellular RNA was extracted, as described (22), from Fraction I, Fraction II-III and Fraction IV-V combined, separated from either proximal or distal hepatocytes. Eight milliliters of a solution containing $4 \mathrm{M}$ guanidine isothiocyanate, 0.5 sodium $N$-laurylsarcosine, $25 \mathrm{mM}$ sodium citrate and $100 \mathrm{mM}$ 2-mercaptoethanol ( $\mathrm{pH} \mathrm{7.0)}$ were used per milliliter of cell suspension. The volumes of reagents used in subsequent steps were always adjusted per milliliter of original cell suspension. Poly(A+)RNA was separated by chromatography in oligo(dT)cellulose columns as described (23).

Northern Blots: $\quad$ Poly $(\mathrm{A}+) \mathrm{RNA}$, separated from the various cell fractions obtained by elutriation of proximal or distal hepatocytes, was loaded into $1 \%$ agarose gels containing $2.2 \mathrm{M}$ formaldehyde (24), and the electrophoresis ran for $4 \mathrm{hr}$ at $5 \mathrm{~V}$ per $\mathrm{cm}$. Formaldehyde-denatured poly $(\mathrm{A}+) \mathrm{RNA}$ was transferred into nitrocellulose filters, and the filters were air dried and baked for $2 \mathrm{hr}$ at $80^{\circ} \mathrm{C}$ under vacuum.

Hybridization and Autoradiography of Northern Blots: A cDNA recognizing sequences of both cytochromes $\mathrm{P}-450 \mathrm{~b}$ mRNA and P-450e was a generous gift of Dr. M. Adesnik (New York University). This rat liver cDNA, cloned into pBR322, corresponds to clone R17. The cDNA insert of $1.1 \mathrm{~kb}$ encodes for the $\mathrm{COOH}$ terminal 211 amino acids of a polypeptide containing amino acid residues found primarily in cytochrome P-450e (16).

Nitrocellulose filters were prehybridized for $2 \mathrm{hr}$ at $65^{\circ} \mathrm{C}$ in a solution containing: (a) $6 \times 0.9 \mathrm{M}$ sodium chloride:0.1 $\mathrm{M}$ sodium citrate: $0.5 \%$ sodium dodecyl sulfate (SSC); (b) $5 \times$ Denhardt's solution (1\% Ficoll, $1 \%$ polyvinylpyrrolidone and $1 \%$ bovine serum albumin), (c) and $100 \mu \mathrm{g}$ per ml of denatured salmon sperm DNA. R17 was nick-translated (25) using [ $\alpha$ $\left.{ }^{32} \mathrm{P}\right] \mathrm{ATP}$ (3,000 $\mathrm{Ci}$ per mmole, Amersham Corp., Arlington Heights, Ill.). Hybridization was performed at $65^{\circ} \mathrm{C}$ for $16 \mathrm{hr}$ in a solution containing $0.9 \mathrm{M}$ sodium chloride, $0.1 \mathrm{M}$ sodium citrate, $0.5 \%$ sodium dodecyl sulfate, $5 \times$ Denhardt's solution, $0.01 M$ EDTA, $100 \mu \mathrm{g}$ per $\mathrm{ml}$ of denatured salmon sperm DNA and $75 \mathrm{ng}$ per $\mathrm{ml}$ of $\left[\alpha{ }^{32} \mathrm{P}\right]$-labeled cDNA probe.

Filters were washed with: (a) $2 \times \mathrm{SSC}: 0.5 \%$ sodium dodecyl sulfate for $5 \mathrm{~min}$; (b) $2 \times$ SSC:0.1\% sodium dodecyl sulfate for $15 \mathrm{~min}$ [both washings (a and b) were performed at room temperature], and (c) $0.1 \times$ SSC:0.5\% sodium dodecyl sulfate for $2 \mathrm{hr}$ at $65^{\circ} \mathrm{C}$, followed by changing to a fresh buffer and further incubation for $30 \mathrm{~min}$. Autoradiography was performed using Kodak X-Omat AR film between two intensifying screens at $-70^{\circ} \mathrm{C}$. To assess nonspecific hybridization, filters were hybridized with $\left[{ }^{32} \mathrm{P}\right]$-labeled pBR322. To assess the specificity of the PB effect, hybridization was also performed with $\left[\alpha^{-32} \mathrm{P}\right]$ -labeled albumin cDNA clone obtained from mouse liver (clone pmalb2 was a generous gift of Dr. S. Tilghman) (26). In addition to corresponding controls, a sample (the same in all Northerns) was introduced into each Northern blot as an internal standard.

Densitometric Analysis: Densitometric analysis was per- 
formed on autoradiographs using a laser-activated LKB densitometer. Integration and statistical analysis were performed on an Apple II linked to the densitometer using Gelscan software (LKB Instruments, Inc., Gaithersburg, Md.). Samples to be compared were usually loaded into the same gels in order to establish comparisons between levels of mRNA in the various fractions. If this was not possible, internal standards (samples previously hybridized in recent experiments) were run in the same gels in which the new samples were assessed. In addition, control (noninduced) samples were run in each gel. Therefore, levels of mRNA have been calculated in relationship to the respective control value in each gel and expressed as arbitrary densitometric units.

\section{Determination of Total Cytochrome P-450}

Total cytochrome P-450 content was measured (27) in microsomes isolated, as described (28), from Fractions I, II-III and IV-V. Microsomes were isolated from each hepatocyte fraction in controls as well as after 16,33 and $48 \mathrm{hr}$ of PB administration. Using sodium dithionite as the reducing agent, the absorbance spectrum was measured simultaneously in the carbon monoxide-treated sample and in the control. Differences in absorbance were determined at 490 and 450 microunits in an Aminco spectrophotometer. An extinction coefficient of 91 $\mathrm{m} M \times \mathrm{sec}^{-1}$ was used in calculations as described (29). Total cytochrome P-450 content was expressed either as nmoles per milligram protein or as nmoles per $10^{6}$ hepatocytes. Protein determinations were performed as described (30). The number of hepatocytes in each elutriated fraction was determined in a hemocytometer under light microscopy (Leitz, Dialux). All measurements of cytochrome P-450 content were performed in microsomal pellets stored overnight at $-20^{\circ} \mathrm{C}$. This storage resulted in less than $15 \%$ loss of cytochrome $P-450$. It should be noted that, in the initial validation of the method, acridine orange was used to assess the origin of the isolated hepatocytes. However, labeling with this fluorescent substance was discontinued once preliminary experiments with acridine orange established: (a) the proximal or distal origin of the isolated hepatocytes in controls and after PB administration and (b) that the presence of acridine orange in hepatocytes was not necessary for separation of proximal and distal hepatocytes in Percoll gradients. Periodically throughout these experiments, a "quality control" experiment containing acridine orange was repeated to assure that the same original results were obtained. Therefore, all measurements of cytochrome P-450 mRNAs and protein were performed in the absence of acridine orange in hepatocytes.

\section{RESULTS AND DISCUSSION}

\section{Cytochromes P-450b and P-450e mRNA Levels in Proximal and Distal Hepatocytes}

To define the kinetics of induction in each hepatocyte fraction, cytochromes $\mathrm{P}-450 \mathrm{~b}$ and $\mathrm{P}-450 \mathrm{e} \mathrm{mRNAs}$ were measured at various intervals after a single injection of PB. Since the cDNA probe used in these experiments recognized sequences of both cytochromes $\mathrm{P}-450 \mathrm{~b}$ and P-450e mRNAs, the data presented here have been analyzed as if reflecting the measurements of both mRNAs. However, studies using synthetic oligonucleotide probes recognizing either cytochromes $\mathrm{P}-450 \mathrm{~b}$ or $\mathrm{P}-450 \mathrm{e}$ mRNAs have indicated that the levels of cytochrome P-450b mRNA were 4- to 5-fold greater than those of cytochrome P-450e after PB administration (15). Therefore, the individual response of either cytochromes $P$ $450 \mathrm{~b}$ or P-450e mRNAs to PB in each of the cell fractions will have to be assessed with probes specific for each of these cytochromes.

Figure 1 (A and B) illustrates autoradiograms of Northern blots obtained at various intervals of time after the single injection of PB. Figure 2 shows the corresponding densitometric analyses. All hepatocytes were found to transcribe the PB-inducible cytochromes $\mathrm{P}-450 \mathrm{~b}$ and $\mathrm{P}-450 \mathrm{e}$ mRNAs. In all fractions, the inductive curve was similar. Maximal mRNAs levels were attained $16 \mathrm{hr}$ after the injection of $P B$ and returned to basal values by 48 hr. A 20- to 25-fold increment in cytochromes P-450b and P-450e mRNAs over control values was obtained in hepatocytes separated in Fractions I and II-III after a retrograde perfusion. Finally, the levels of cytochromes P-450b and P-450e mRNAs were 2- to 3-fold higher in distal than in proximal hepatocytes. Figure 3 shows the kinetics of induction of total cytochrome $P-450$ protein when the data were expressed per milligram of microsomal protein. After a single injection of $\mathrm{PB}$, the kinetics of induction in the three cell fractions separated from proximal or distal hepatocytes were similar. Maximal cytochrome P-450 induction was obtained after $33 \mathrm{hr}$, returning to basal values after $48 \mathrm{hr}$. As shown in Figure $3 \mathrm{~B}$, a similar set of curves were obtained when the data were expressed as nmoles per $10^{6}$ hepatocytes. Therefore, a lag period of about $17 \mathrm{hr}$ between maximal induction of mRNAs and maximal induction of cytochrome P-450 protein was noted in these experiments. During this period, mRNAs were translated and the apoprotein assembled into the hemoprotein. A recent study using whole liver showed that the kinetics of induction of the cytochromes P-450b and P-450e apoprotein by PB was identical to the kinetics of induction of total cytochrome P-450 determined spectrophotometrically (31). Moreover, after a single injection of $\mathrm{PB}$, the lag period for the induction of the mRNAs as well as that of the apoproteins were similar to the intervals described in this study. Differences between hepatocytes isolated from the proximal and distal halves of the acinus were more noticeable at the level of the specific mRNAs than at the level of total cytochrome $\mathrm{P}-450$ protein. While these results may suggest that there might be differences in translational efficiency of the mRNAs in the various fractions, caution should be exerted in the interpretation of these data. While levels of cytochromes P-450b and P-450e mRNAs were measured specifically and by a sensitive method, levels of total cytochrome P-450 content were determined spectrophotometrically, and therefore, all cytochrome P-450 forms capable of responding to PB contributed to these results.

The most significant finding of these experiments was that the kinetics of induction following a single dose of PB was similar in all hepatocyte fractions, and the lag period between maximal induction of mRNAs and total cytochrome P-450 activity was also the same. However, the levels of cytochromes P-450b and P-450e mRNAs induction were consistently higher in fractions isolated from distal hepatocytes.

To assess whether the differences in the levels of cytochrome P-450 mRNAs depended on variations in recovery of mRNAs in each elutriated fraction as well as the specificity of the PB effect, levels of albumin mRNA 
CONTROL PHENOBARBITAL

$$
\ulcorner 6 \longrightarrow\ulcorner-16 \longrightarrow\ulcorner 24 \neg\ulcorner 33 \longrightarrow
$$

I III III I IE III I III IXI I III ITI IE IY

A

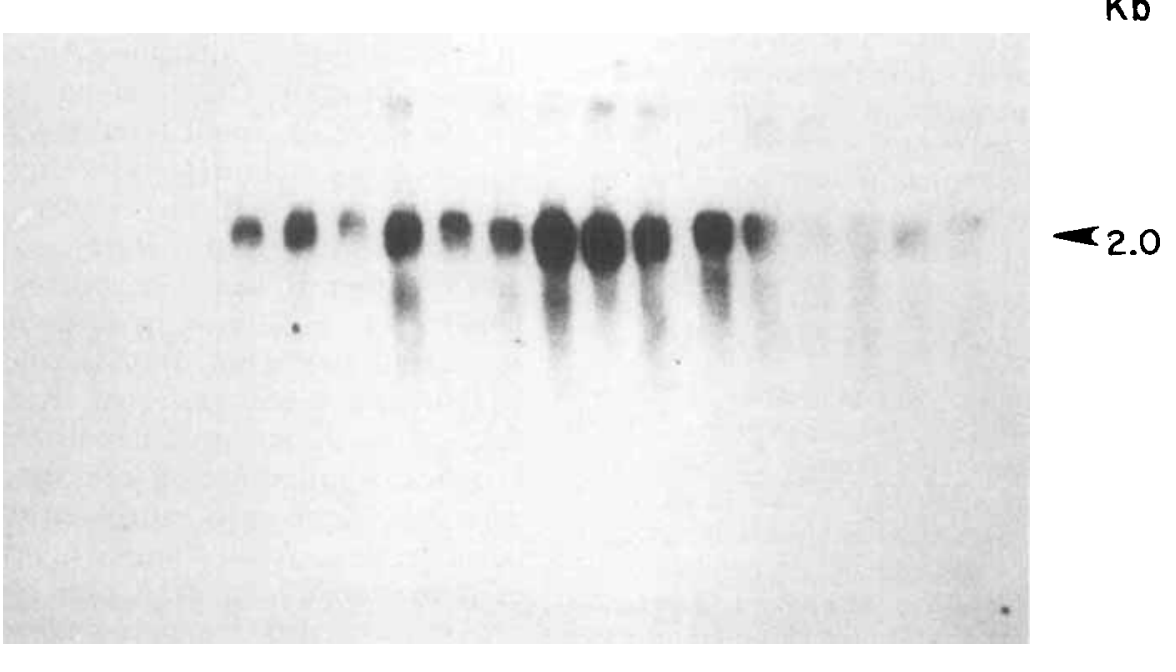

\section{Proximal Hepatocytes}

CONTROL

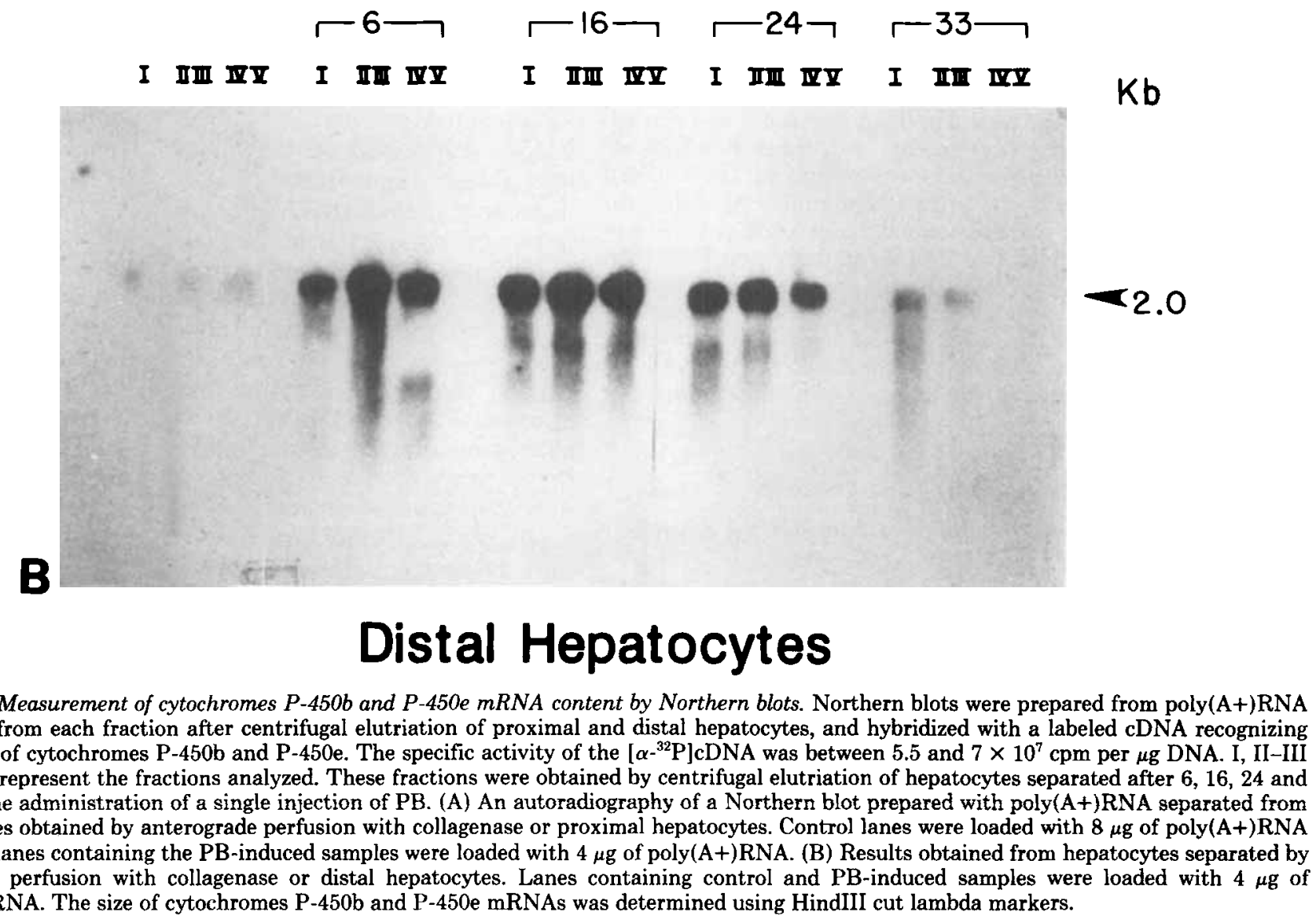

\section{PHENOBARBITAL}

I III III I IIII IFY I III IFY
FIG. 1. Measurement of cytochromes $P-450 b$ and P-450e mRNA content by Northern blots. Northern blots were prepared from poly(A+)RNA extracted from each fraction after centrifugal elutriation of proximal and distal hepatocytes, and hybridized with a labeled cDNA recognizing sequences of cytochromes P-450b and P-450e. The specific activity of the $\left[\alpha^{-3}{ }^{32} \mathrm{P}\right] \mathrm{cDNA}$ was between 5.5 and $7 \times 10^{7} \mathrm{cpm}$ per $\mu \mathrm{g}$ DNA. I, II-III and IV-V represent the fractions analyzed. These fractions were obtained by centrifugal elutriation of hepatocytes separated after $6,16,24$ and $33 \mathrm{hr}$ of the administration of a single injection of PB. (A) An autoradiography of a Northern blot prepared with poly(A+)RNA separated from hepatocytes obtained by anterograde perfusion with collagenase or proximal hepatocytes. Control lanes were loaded with $8 \mu \mathrm{g}$ of poly(A+)RNA while the lanes containing the PB-induced samples were loaded with $4 \mu \mathrm{g}$ of poly(A+)RNA. (B) Results obtained from hepatocytes separated by retrograde perfusion with collagenase or distal hepatocytes. Lanes containing control and PB-induced samples were loaded with $4 \mu \mathrm{g}$ of poly(A+)RNA. The size of cytochromes $\mathrm{P}-450 \mathrm{~b}$ and $\mathrm{P}-450 \mathrm{e}$ mRNAs was determined using HindIII cut lambda markers. 


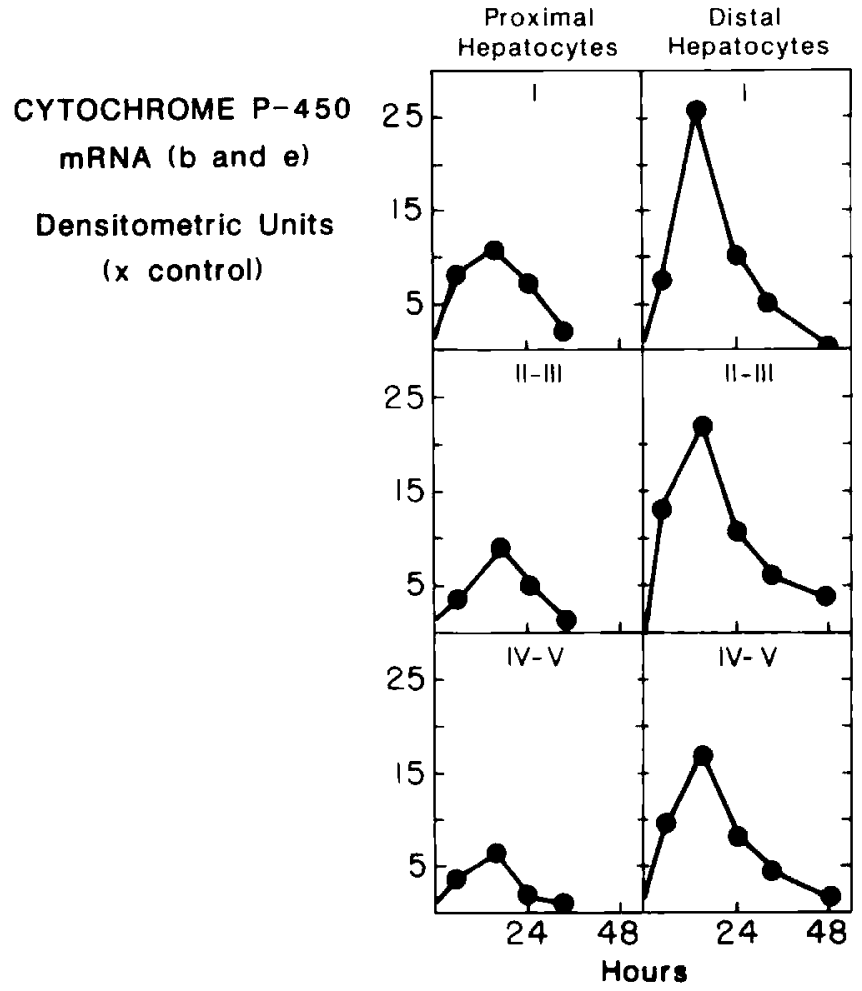

Fig. 2. Cytochromes P-450b and P-450e mRNAs: densitometric analysis of autoradiographs. Results have been expressed in arbitrary densitometric units per $4 \mu \mathrm{g}$ of poly $(\mathrm{A}+) \mathrm{RNA}$. These values have been expressed in relationship to the respective controls present in the same gels. The meaning of Fractions I, II-III and IV-V is described in Fig. 1. Values represent the mean of two experiments per time interval. Densitometric analysis was performed using a laser-activated LKB densitometer linked to an Apple computer. Statistical analysis of curves and integration of areas under curves were performed using a Gelscan program (LKB).

were also measured at various intervals after $\mathrm{PB}$ administration. Figure 4 shows the data obtained using Fraction II-III separated by elutriation of distal hepatocytes. A 1.5-fold increment in the levels of albumin mRNA was detected. This should be compared to a 20 -fold increment in cytochromes P-450b and P-450e mRNAs observed in this fraction. In addition, there were no differences in the levels of albumin mRNA among all fractions isolated from control livers (data not shown), in agreement with recent data obtained by in situ hybridization (32). These results indicated that it was unlikely that the increased levels of cytochromes P-450b and P-450e mRNAs, measured in distal hepatocytes after PB administration, were due to a higher recovery of poly $(\mathrm{A}+) \mathrm{RNA}$ from distal hepatocytes. To assess nonspecific hybridization, control hybridizations were performed using $\left[{ }^{32} \mathrm{P}\right]$-labeled pBR322. Under these conditions, levels of nonspecific hybridization were undetectable.

Studies performed in whole liver $(16,17)$, which did not take into consideration the heterogeneity of hepatocytes, have been interpreted as indicating that the induction of liver cytochrome $\mathrm{P}-450$ by $\mathrm{PB}$ is the result of an increased rate of transcription of specific mRNAs. This proposal for increased transcription rates was formulated after levels of mRNA, as well as in vitro nuclear run-off studies, were performed using isolated nuclei (17). In this study, rates of elongation of nascent RNA chains were not measured. Therefore, while the data generated in this study are compatible with such a proposal, the differences in mRNA levels found in the various cell fractions may have been due to either a faster rate of transcription of cytochromes P-450b and P-450e mRNAs in distal hepatocytes or to a prolonged half-life of the mRNAs in these hepatocytes. The possibility that RNA may have been degraded to a different extent in proximal and distal hepatocytes during cell separation cannot be ruled out. However, during the assessment of Northern blots, significant degradation of RNA was not observed neither when the cytochrome $\mathrm{P}-450$ probe or the albumin probe was used. This possibility seemed therefore, unlikely.

While these data indicate that proximal or distal hepatocytes separated by directional perfusion with collagenase responded to PB heterogeneously, two types of experiments are needed to further clarify these data: (a) the location within the acinus of the three cell fractions isolated from either proximal or distal hepatocytes has to be defined by a different approach, such as by in situ hybridization techniques and (b) the molecular mechanisms responsible for the heterogenous response of hepatocytes to PB may be further defined by in vitro runoff studies using nuclei isolated from each of the hepatocyte fractions.

In summary, hepatocytes comprising the liver acinus, the functional unit of hepatic parenchyma, have been first separated into proximal or distal hepatocytes by anterograde or retrograde perfusions with collagenase and then further fractionated into three arbitrary populations by centrifugal elutriation. This approach has enabled us to define the kinetics of mRNA induction for proximal and distal hepatocytes. In addition, these data have defined, at the mRNA level, that the response of acinar hepatocytes to $\mathrm{PB}$ induction of cytochrome $\mathrm{P}-450$ is heterogeneous; thus providing an additional step in the definition of the molecular mechanisms responsible for the heterogenous response of acinar hepatocytes to PB, previously defined only at the protein level by immunofluorescence studies (18-20). Hepatocytes isolated from the distal half of the acinus, those apparently exposed to the lowest concentrations of substrates and oxygen, responded to PB with higher levels of cytochromes P-450b and P-450e mRNAs. In essence, this study indicates that, while it is plausible that an increased rate of transcription of cytochromes $P-450 \mathrm{~b}$ and P-450e mRNAs may be responsible for the observed increment in cytochrome $\mathrm{P}-450$ protein after $\mathrm{PB}$, this response is heterogenous. There is a second level of gene regulation occurring within the liver acinus which has now been defined at the level of cytochromes $P-450 \mathrm{~b}$ and P-450e mRNAs. The result of this intraacinar modulation is the heterogeneous expression of the induced cytochrome P-450 protein. To this extent, the method of isolation hepatocytes used in this study provides a tool for the study of the effects of the cellular microenvironments on the zonal expression of the PB-inducible cytochrome P-450 genes. 


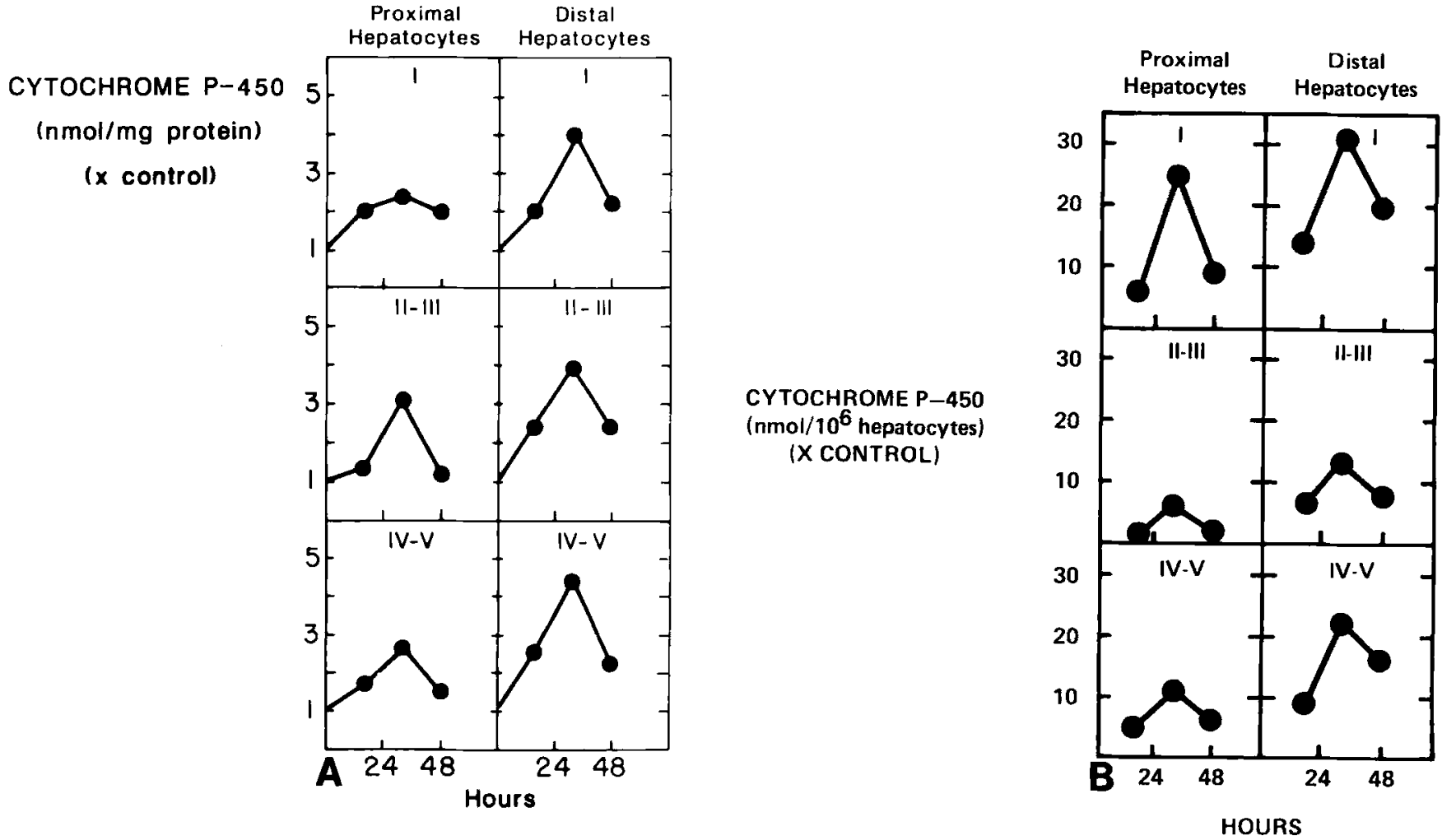

FIG. 3. The induction of total cytochrome $P-450$ measured in microsomes isolated from hepatocyte fractions separated after a single injection of $P B$. Proximal or distal hepatocytes refer to hepatocytes separated after anterograde or retrograde perfusions with collagenase followed by centrifugal elutriation, respectively. Measurements were performed in microsomes isolated from each of the three fractions (I, II-III and IV-V). Intervals analyzed were: $0,16,33$ and $48 \mathrm{hr}$ after a single i.p. injection of PB. Mean represents two experiments per point. Results have been expressed either as nmoles per milligram microsomal protein (A) or as nmoles per $10^{6}$ hepatocytes (B), in relationship to control values.

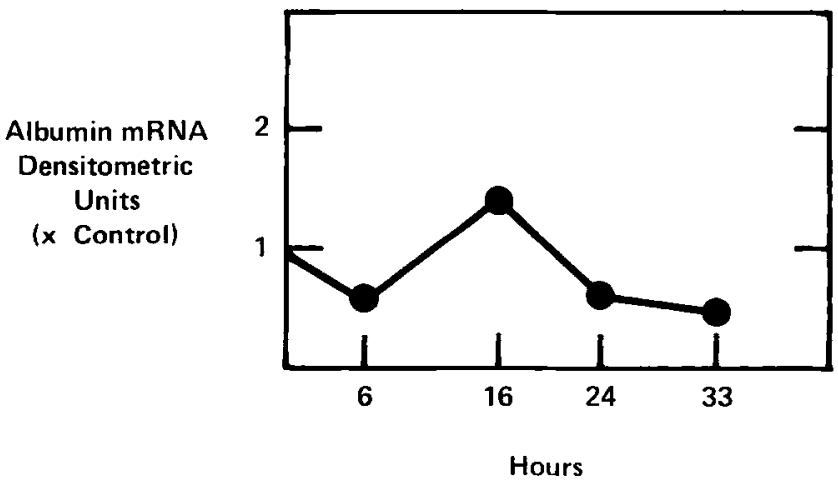

FIG. 4. Effect of $P B$ on albumin mRNA: densitometric analysis of autoradiographs. Fraction II-III was obtained after centrifugal elutriation of distal hepatocytes. This fraction was separated after $6,16,24$ and $33 \mathrm{hr}$ after a single dose of PB ( $80 \mathrm{mg}$ per $\mathrm{kg}$ ), as well as after similar intervals after the injection of the solvent (controls). Four micrograms of poly $(A+) R N A$, separated at each time interval, were loaded in the same agarose gel, blotted into nitrocellulose filters and hybridized. Hybridization was performed using $\left[\alpha{ }^{32}\right.$ P]ATP albumin cDNA clone. Densitometric analysis was performed using a laseractivated LKB densitometer (Gelscan program). Results have been expressed in arbitrary densitometric units.

Acknowledgments: The authors express their appreciation to Drs. M. Adesnik and S. Tilghman for making the cytochrome P-450 and albumin clones, respectively, available for this study.

\section{REFERENCES}

1. Rappaport AM. Liver and biliary tract physiology. Javitt ND, ed. Baltimore, Maryland: University Park Press, 1980: 1-63.
2. Jones AL, Schmucker DL, Mooney JS, et al. Morphometric analysis of rat hepatocytes after total biliary obstruction. Gastroenterology 1976; 71:1051-1061.

3. Loud AV. A quantitative stereological description of the ultrastructure of normal rat liver parenchymal cells. J Cell Biol 1968; 37:2746.

4. Grisham JW. A morphologic study of deoxyribonucleic acid synthesis and cell proliferation in regenerating rat liver; autoradiography with thymidine- $\mathrm{H}^{3}$. Cancer Res $1962 ; 22: 842-849$.

5. Katz N, Jungermann K. Autoregulatory shift from fructolysis to lactate gluconeogenesis in rat hepatocytes suspensions. The problem of metabolic zonation of liver parenchyma. Hoppe Seylers $\mathrm{Z}$ Physiol Chem 1976; 357:359-375.

6. Novikoff AB. Cell heterogeneity within the hepatic lobule of the rat (staining reactions). J Histochem Cytochem 1959; 7:240-244.

7. Chen EH, Gumucio JJ, Ho NH. Hepatocytes of zones 1 and 3 conjugate sulfobromophthalein with glutathione. Hepatology 1984; 4:467-476.

8. Gumucio JJ, Balabaud CP, Miller DL, et al. HD, Stocker TJ and Franzblau DR. Bile secretion and liver cell heterogeneity in the rat. J Lab Clin Med 1978; 91:350-362.

9. Jones AL, Hradek GT, Renston $\mathrm{RH}$, et al. Autoradiographic evidence for hepatic lobular concentration gradient of bile acid derivate. Am J Physiol 1980; 238:G223-G237.

10. Thurman RG, Kauffman FC. Sublobular compartmentation of pharmacologic events (SCOPE): metabolic fluxes in periportal and pericentral regions of the liver lobule. Hepatology $1985 ; 1: 144-157$.

11. Rappaport AM. The microcirculatory hepatic unit. Microvas Res $1973 ; 6: 212-228$.

12. Haugen DA, Van Der Hoeven TA, Coon MJ. Purified liver microsomal cytochrome P-450. J Biol Chem 1975; 250:3567-3570.

13. Ryan DE, Thomas PE, Levin W. Purification and characterization of a minor form of hepatic microsomal cytochrome P-450 from rats treated with polychlorinated biphenyls. Arch Biochem Biophys 1982; 216:272-288.

14. Botelho LH, Ryan DE, Levin W. Amino acid composition and partial amino acid sequences of three highy purified forms of liver microsomal cytochrome $\mathrm{P}-450$ from rats treated with polychlori- 
nated byphenyls, phenobarbitol, or 3-methylcholanthrene. J Biol Chem 1979; 254:5635-5640.

15. Omiecinski CJ, Walz FG, Vlasuk GP. Phenobarbitol induction of rat liver cytochromes $\mathrm{P}-450 \mathrm{~b}$ and $\mathrm{P} .450$ e. J Biol Chem 1985; 260:3247-3250.

16. Adesnik M, Bar-Nun S, Maschio F, et al. Mechanism of induction of cytochrome P-450 by phenobarbital. J Biol Chem 1981; 256:10340-10345.

17. Hardwick JP, Gonzalez FJ, Kasper CB. Transcriptional regulation of rat liver epoxide-hydratase, NADPH-cytochrome P-450 oxidoreductase and cytochrome P-450 genes by phenobarbital. J Biol Chem 1983; 258:8081-8085.

18. Gooding PE, Chayen J, Sawyer B, et al. Cytochrome P-450 distribution in rat liver and the effect of sodium phenobarbitone administration. Chem Biol Interactions 1978; 20:299-310.

19. Baron J, Rednick JA, Guengerich P. An immuno-histochemical study on the localizations and distributions of phenobarbital and 3 -methylcholanthrene-inducible cytochromes $P-450$ within the livers of untreated rats. J Biol Chem 1981; 256:5931-5937.

20. Baron J, Rednick JA, Guengerich P. Effects of 3-methylcholanthrene-inducible isozyme of cytochrome $\mathrm{P}-450$ within centrilobular, midzonal, and periportal hepatocytes. J Biol Chem 1983; 257:953-957.

21. Gumucio JJ, May M, Dvorak C, et al. The isolation of functionally heterogeneous hepatocytes of the proximal and distal half of the liver acinus in the rat. Hepatology 1986; 6:932-944.

22. Chirgwin JM, Przybyla AE, MacDonald RJ, et al. Isolation of biologically active ribonucleic acid from sources enriched in ribonuclease. Proc Natl Acad Sci USA 1979; 18:5294-5299.
23. Aviv H, Leder P. Purification of biologically active globin messenger RNA by chromatography on oligothymidilic acid cellulose. Proc Natl Acad Sci USA 1972; 69:1408-1412.

24. Maniatis T, Fritsch EF, Sambrook J. Molecular cloning. A laboratory manual. New York: Cold Spring Harbor Laboratory, 1982: 202-203.

25. Rigby PWJ, Dieckmann M, Rhodes M. Labeling deoxyribonucleic acid to high specific activities in vitro by nick translation with DNA polymerase. I. J Molec Biol 1977; 113:237-251.

26. Tilghman SM, Belayew A. Transcriptional control of the murine albumin/ $\alpha$-fetoprotein locus during development. Proc Natl Acad Sci USA 1982; 79:5254-5257.

27. Omura $T$, Sato $R$. The carbon monoxide-binding pigment of liver microsomes. I Biol Chem 1964; 239:2379-2385.

28. Gumucio JJ, De Mason L, Miller DL, et al. Induction of cytochrome P-450 in a selective sub-population of hepatocytes. Am J Physiol 1978; 234:C102-C109.

29. Estabrook RW, Peterson J, Baron J, et al. Principles of spectrophotometric measurements of turbid suspensions. Meth Pharmacol $1972 ; 2: 303-350$.

30. Lowry HO, Rosebrough NJ, Farr AL, et al. Protein measurement with Folin phenol reagent. J Biol Chem 1951; 193:265-275.

31. Ravishankar H, Padmanaban G. Turnover of messenger RNA, apoprotein and haem of cytochrome $P-450 \mathrm{~b}$ and $\mathrm{e}$ induced by phenobarbitone in rat liver. Biochem J 1985; 229:73-79.

32. Bernuau D, Poliard A, Tournier J, et al. All hepatocytes are involved in the expression of the albumin gene in the normal adult rat: a demonstration by in situ hybridization and immunoperoxidase technique. Cell Biol Int Rept 1985; 9:31-42. 